\title{
Endoscopically guided percutaneous suturing to facilitate closure of a large gastrocutaneous fistula with an over-the-scope clip
}

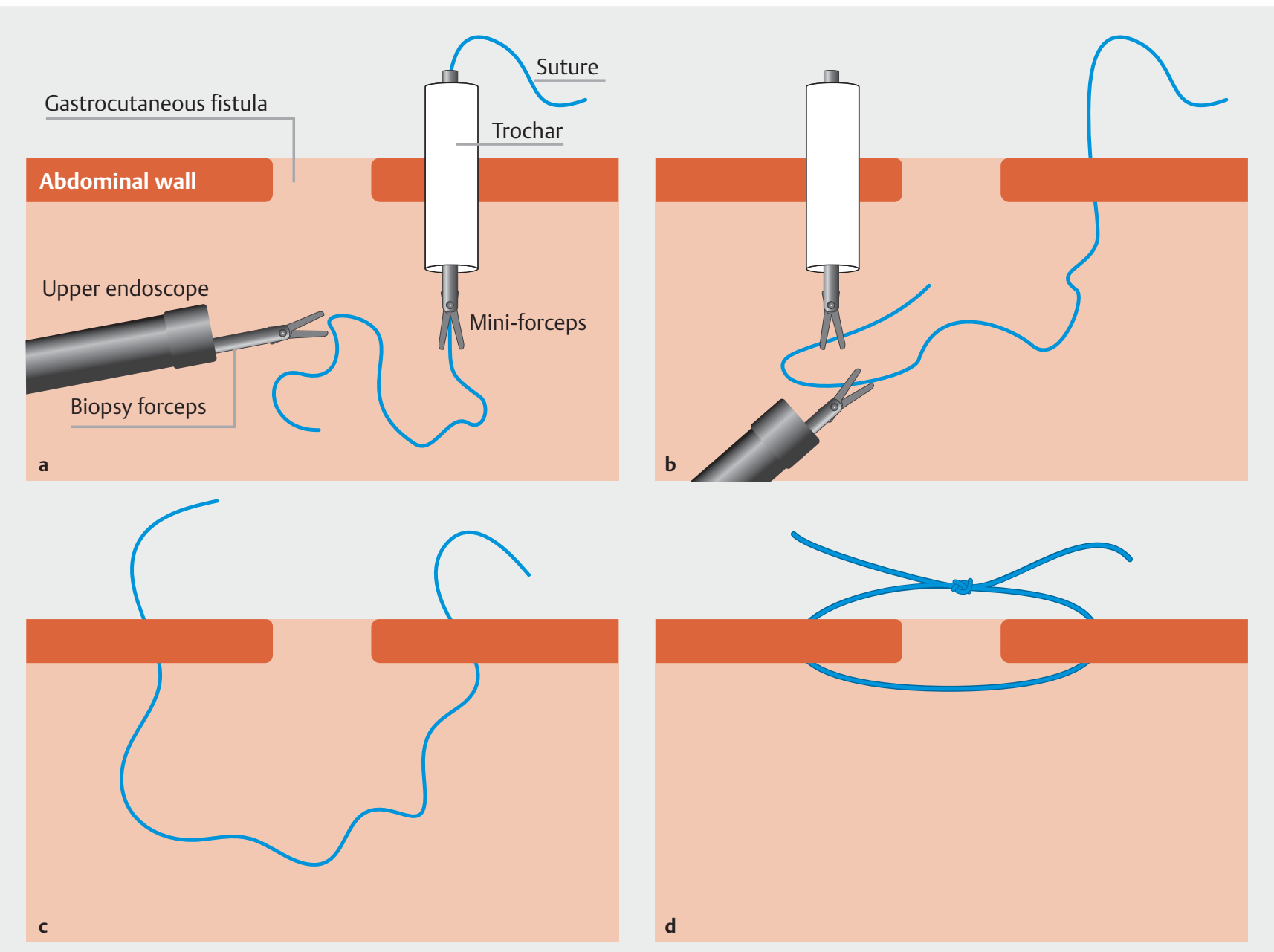

- Fig. 1 Percutaneous endoscopic suturing procedure. a A trocar was passed alongside the gastrocutaneous fistula. A suture was transferred from a mini-forceps via the trocar to a biopsy forceps in the stomach. $\mathbf{b}$ The suture was grasped by the biopsy forceps and then transferred back to the mini-forceps placed through the trocar at a different location. $\mathbf{c}, \mathbf{d}$ The suture was tied on the cutaneous side.

Persistent gastrocutaneous fistula (GCF) after percutaneous endoscopic gastrostomy (PEG) tube removal is an uncommon complication [1]. Advances in endoscopy have enabled endoscopic closure of these defects with a multitude of modalities, including argon plasma coagulation (APC), endoscopic suturing, and over-the-scope clips (OTSCs) [2-4]. Percutaneous endoscopic suturing has recently been described for closure of GCF ( $\triangleright$ Fig. 1, > Video 1) [5].
We describe the case of a 24-year-old man with a history of acquired immunodeficiency syndrome and disseminated Mycobacterium avium complex, who was not compliant with medical treatment. For 6 months he had experienced increasing discharge from a former PEG site (the PEG tube had been removed 10 years previously). On upper endoscopy he had a large GCF (> Fig.2). APC was applied to the fistula tract and surrounding tissue (> Fig.3). Two interrupted sutures were used to close the defect using the overstitch device (Apollo Endosurgery, Austin, Texas, USA). The was no evidence of a leak from the cutaneous side of the fistula after closure. The patient resumed a full diet and was placed on acid suppression therapy.

He re-presented 2 weeks later with recurrent leakage from the GCF. On upper endoscopy, the GCF had reopened and the sutures had loosened (> Fig.4). APC was again applied to the GCF. Then, two 


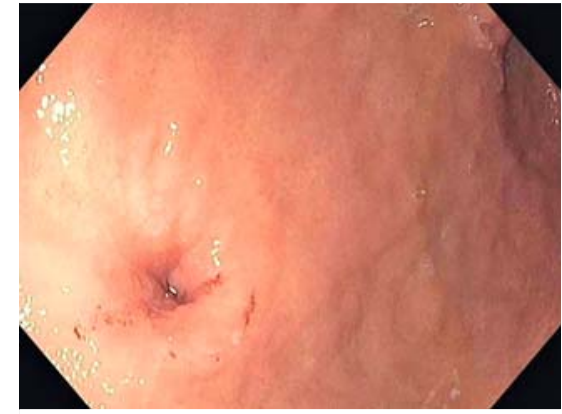

- Fig. 2 Gastrocutaneous fistula.

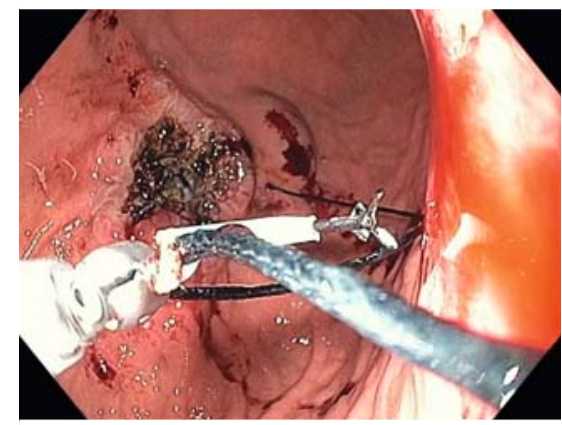

- Fig. 5 Transfer of suture from mini-forceps to biopsy forceps during endoscopically guided percutaneous suturing.

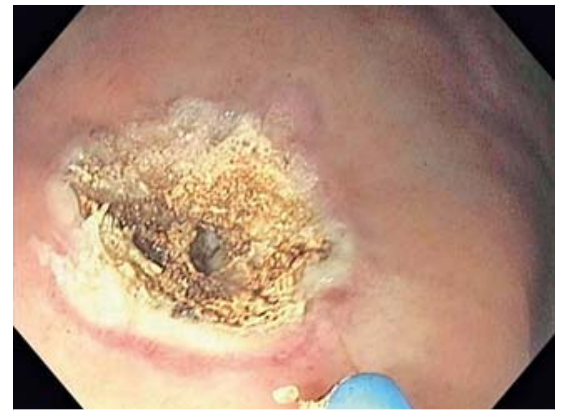

- Fig. 3 Argon plasma coagulation of mucosa surrounding the gastrocutaneous fistula.

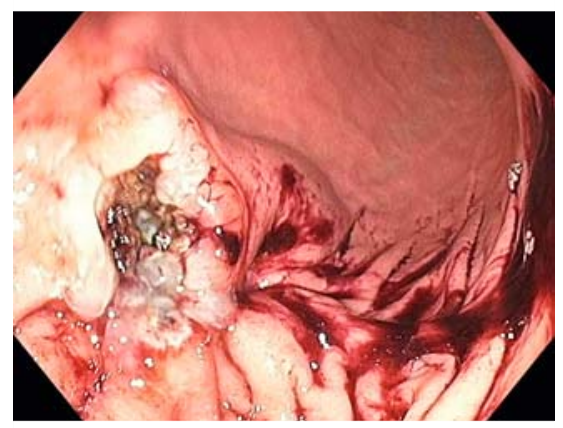

- Fig. 6 Approximation of gastrocutaneous fistula after endoscopically guided percutaneous suturing.

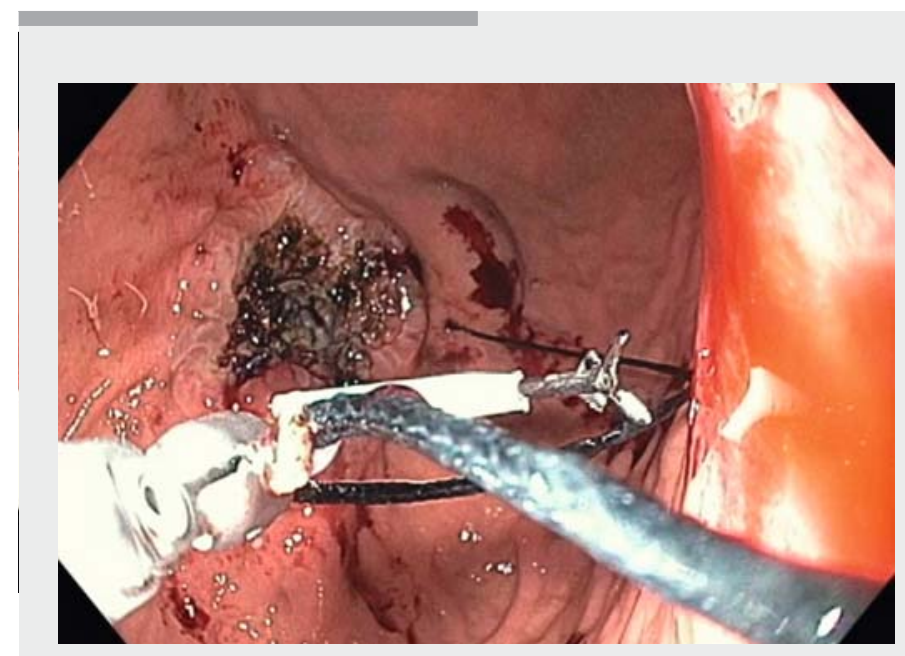

$\checkmark$ Video 1 Endoscopically guided percutaneous suturing to facilitate closure of a large gastrocutaneous fistula with an over-the-scope clip.

percutaneous endoscopic sutures were used to close the GCF ( $\triangleright$ Fig.5). After suturing, the edges of the fistula were more closely approximated; however, the fistula remained open ( $\mathbf{F i g . 6}$ ). An OTSC was used to close the fistula, as it was now possible to bring the edges of the fistula into the cap of the OTSC deliv- ery device. There had been no further leakage from the GCF 12 months following the closure.

In large GCFs, percutaneous endoscopic suturing can facilitate the apposition of the gastric mucosal surface to allow complete closure of the fistula tract with an OTSC.

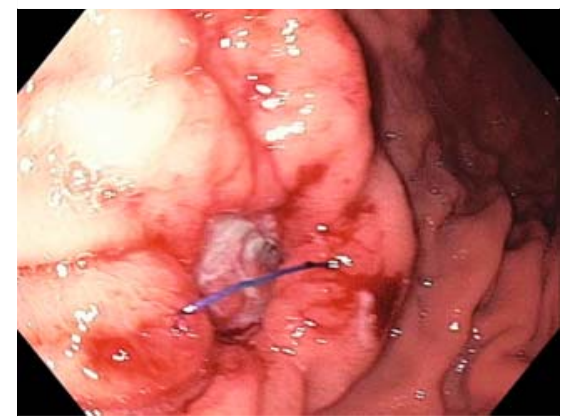

- Fig. 4 Previous endoscopic sutures had loosened and the fistula tract was wide open.

Endoscopy_UCTN_Code_TTT_1AO_2AC

Competing interests

Dr. Khashab is a consultant and is on the medical advisory board for Boston Scientific and Olympus. Dr. Kumbhari is a consultant for Boston Scientific, Apollo Endosurgery, ReShape Life Sciences, and Medtronic.

The authors

Robert A. Moran, Olaya Brewer Gutierrez, Juliana Yang, Tossapol Kerdsirichairat, Omid Sanaei, Vivek Kumbhari, Mouen A. Khashab Division of Gastroenterology and Hepatology, Johns Hopkins Hospital, Baltimore, Maryland, United States

Corresponding author

\section{Mouen A. Khashab, MD}

Division of Gastroenterology and Hepatology, Johns Hopkins Hospital, 1800 Orleans Street, Suite 7125G, Baltimore, MD 21287, United States Fax: +1-410-283-0474 mkhasha1@jhmi.edu

\section{References}

[1] Deen OJ, Parisian KR, Harris C et al. A novel procedure for gastrocutaneous fistula closure. J Clin Gastroenterol 2013; 47: 608 611

[2] Hameed H, Kalim S, Khan YI. Closure of a nonhealing gastrocutaneous fistula using argon plasma coagulation and endoscopic hemoclips. Can J Gastroenterol 2009; 23: $217-219$ 
[3] Weiland T, Fehlker M, Gottwald T et al. Performance of the OTSC System in the endoscopic closure of iatrogenic gastrointestinal perforations: a systematic review. Surg Endosc 2013; 27: $2258-2274$

[4] Kantsevoy SV, Thuluvath PJ. Successful closure of a chronic refractory gastrocutaneous fistula with a new endoscopic suturing device (with video). Gastrointest Endosc 2012; 75: $688-690$

[5] Vasant DH, Abraham A, Paine PA. Endoscopically assisted suturing of a persistent gastrocutaneous fistula by using a site closure device. Gastrointest Endosc 2013; 78 : $553-554$

\section{Bibliography}

DOI https://doi.org/10.1055/a-0640-2303

Published online: 14.8.2018

Endoscopy 2018; 50: E309-E311

(c) Georg Thieme Verlag KG

Stuttgart · New York

ISSN 0013-726X

\section{ENDOSCOPY E-VIDEOS}

https://eref.thieme.de/e-videos

口回 Endoscopy E-Videos is a free 留 自: on interesting cases and new

techniques in gastroenterological endoscopy. All papers include a high quality video and all contributions are freely accessible online.

This section has its own submission website at

https://mc.manuscriptcentral.com/e-videos 